\title{
Modelling and Simulation of Two Gear Electric Vehicle in MATLAB SIMULINK
}

\author{
${ }^{\text {"1}}$ Sudarshan Khond, ${ }^{2}$ Yasir Sheikh, ${ }^{3}$ Mohan Renge \\ 1,2,3 Shri Ramdeobaba College of Engineering and Management, Nagpur \\ Email:khondsr1@rknec.edu, sheikhmn@rknec.edu,rengemm@rknec.edu
}

Received: 16th October 2019, Accepted: 31st January 2020, Published: 30th April 2020

\begin{abstract}
With evolution of Electric drives design for electric vehicles, key aspects such as control, dynamic performance, efficiency and weight-torque ratio are some of the key parameters considered for optimization. Of these, torque to weight ratio is pivotal. As a typical traction load requires high starting torque and low torque during high speed, direct motor coupling may result in oversizing of motor or motor insufficient to drive desired load. Thus to optimize weight, size, cost and torque to weight ratio of an electric drive, gear system is used that provides high torque at standstill to start and accelerate the vehicle and high speed with required torque once the vehicle is set in motion. In this paper we aim to demonstrate Two-gear-Electric vehicle driven using induction motor with $\mathrm{V} / \mathrm{F}$ control where it will be apparent how use of gear box optimises electric drive rating and related parameters.
\end{abstract}

\section{Keywords}

Electric Vehicle, Two Gear, Modelling, Simulation, Design, MATLAB SIMULINK

\section{Introduction}

Modelling and simulation activities have become inseparable part of electric vehicle design from last 4-5 decades. Electric vehicle design presents complexity owing to the interfacing of mechanical-electricalelectronics and to some extent chemical components compared to conventional IC engine-vehicle designs which have well defined techniques and rules with mature simulation tools.[1]

However to increase energy efficiency of the vehicle, reduce $\mathrm{CO}_{2}$ emissions and to avoid penalties set by the governments original equipment manufacturers(OEM's) have now taken task of design and market setting of Hybrid and Electric vehicle very seriously.[4]

One of the most crucial point in Electric vehicle development program are power density $(\mathrm{kW} / \mathrm{Kg})$ and torque to weight ratio.[7] For directly driven electric vehicles, it becomes tough to produce high torque at the start as required by the load and relatively lower torque at high speeds. The problem can be overcome with the help of Two-gear system which scales high torque required to be produced by the motor down and inversely, reduce the speed by same factor.[3]

Model is designed and simulated considering various forces acting on the vehicle, drive control, motor inertia parameters and variable torque and speed scaling factor which will facilitate user to optimize the block for various environment for driving, different control topologies, use of different motor so that customized results for optimum design for particular drive cycles in local area using various topologies for

Smooth and efficient operation can be derived. [6]

Torque-speed Characteristics of Drive and Load

Figure 1(a) shows Torque (Te)-speed characteristics of induction motor operated with V/F control method. As evident from fig., torque generated by the motor remains constant up to rated speed of motor which is achieved by keeping ratio of voltage and frequency constant if speed is increased beyond rated, voltage cannot be increased above rated to prevent damage to the winding insulation. Thus Torque of the motor drops with increase in speed thereby keeping power output $(\mathrm{Pe})$ of motor constant. 


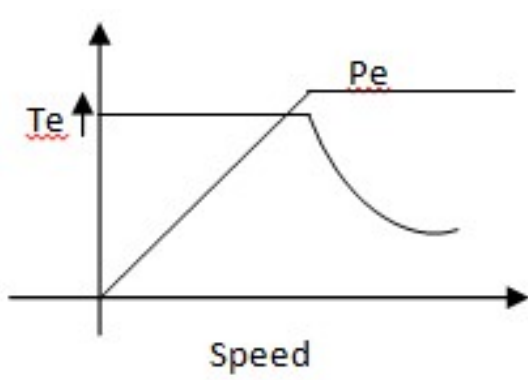

Figure 1(a): Torque, Power-speed Characteristics with V/F Control

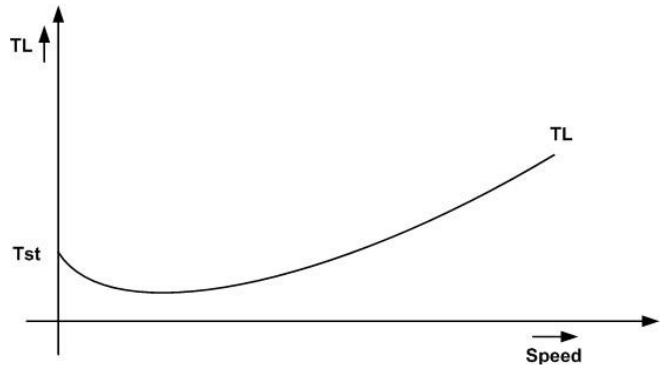

Figure 1(b): Torque-speed Characteristics of a Typical Traction Load

Figure 1(b) shows torque-speed characteristics of load. At standstill position, vehicle is required to overcome stiction. Also to ramp up to a certain value of speed, acceleration torque are also required thus motor needs to produce a high starting torque. However, as vehicle speed increases stiction and acceleration aren't required. [8]

Necessity of Gear Box.

As shown in Figure 2(a), to load motor from its full-load value (T2) to a value close to its maximum loading capacity(T1), Current required(I1) will be 6-7 times that of current required to drive motor with its rated load(I2). Practically considering inertia of vehicle, it takes 6-15 seconds to ramp speed up from 0 to $60 \mathrm{kmph}$ during which time motor will either require 6-7 times full load current or we will have to use motor 6 times of its original capacity. [9]

However once vehicle ramps up to a speed, stiction no longer exists and motor is not required to produce such high amount of toque. Thus to avoid oversizing of motor along with achieving goal of providing high starting torque, gear box is essential. [5]

As shown in Figure 2(b), Torque - speed characteristics of motor is shifted upwards during low speeds to generate sufficient torque, up to T1 (e) to overcome stiction and provide acceleration to the vehicle. Point A corresponds to maximum speed that can be generated in first gear. As gear is changed to increase speed, toque requirement reduces as stiction no longer exists and acceleration torque isn't required in substantial magnitude thus motor can now provide torque up to $\mathrm{T} 2(\mathrm{e})$ in second $\operatorname{gear}(\mathrm{B})$. However once motor operates at point $\mathrm{B}$, torque equilibrium is established and vehicle runs at its top speed for existing loading conditions. [10]

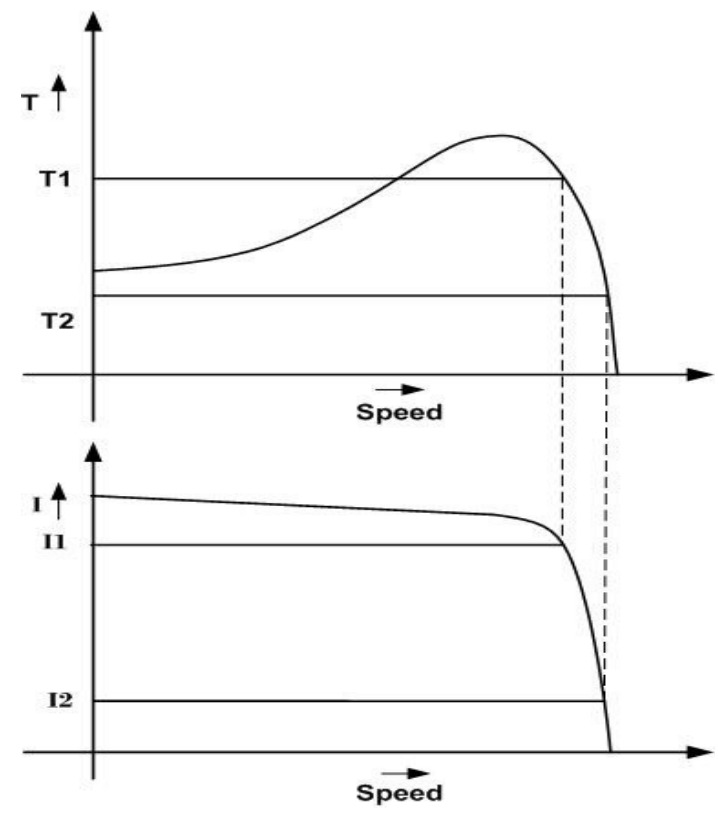

Figure 2 (a): Torque, Current-speed Characteristics of Motor

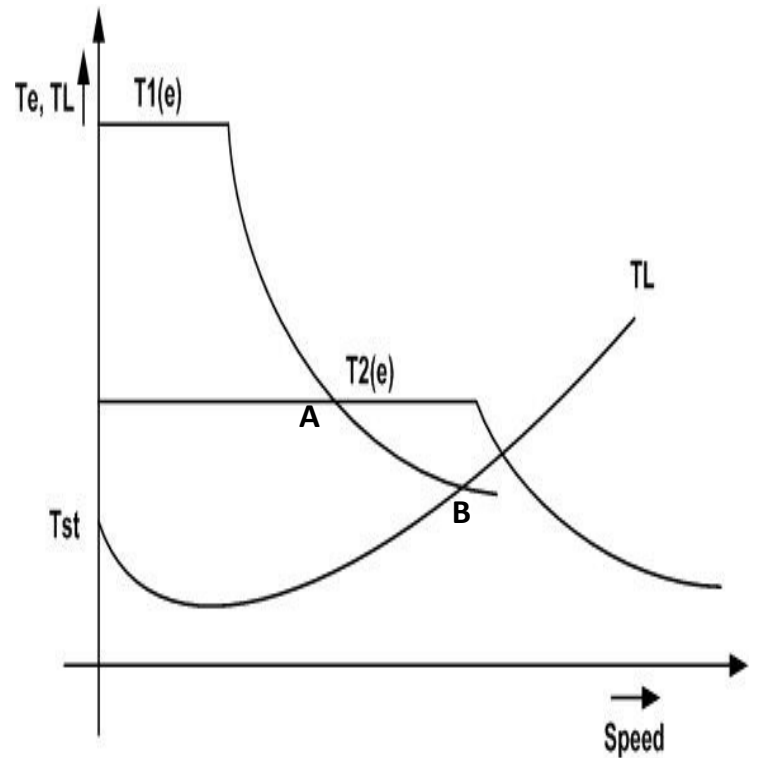

Figure 2(b): Torque-speed Characteristics for Two Gear System 


\section{Block Diagram of Simulation Model}

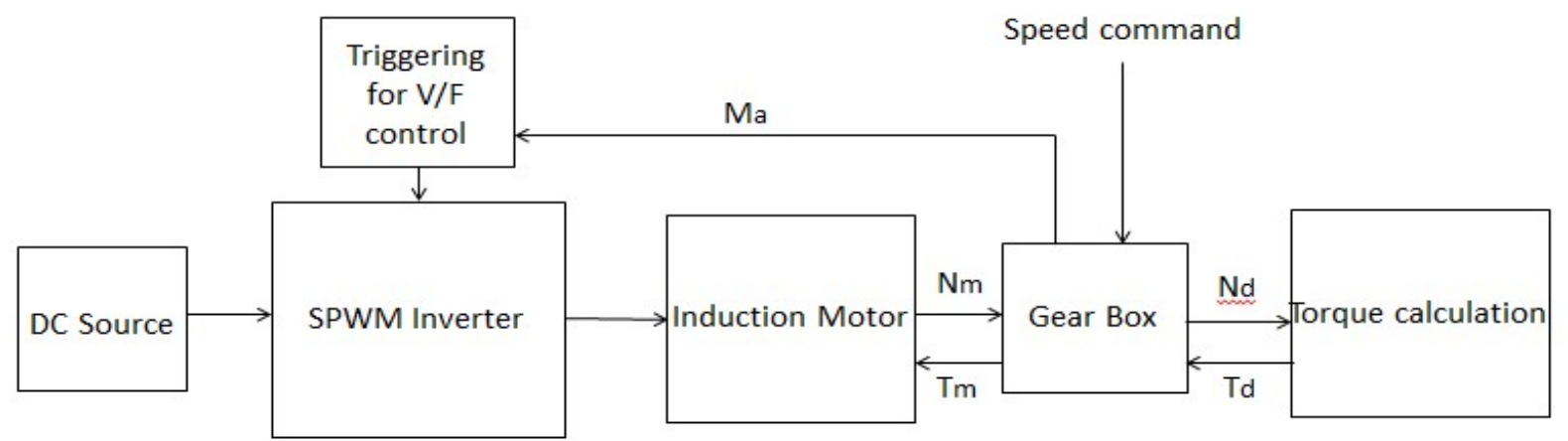

Figure 3: Block Diagram of Simulation Model

Induction motor used here is controlled with $\mathrm{V} / \mathrm{F}$ control where voltage/frequency ratio is kept constant to obtain constant torque up rated voltage. Torque input given to the motor(Tm) is scaled with the help of gear box by selection of appropriate gear ratio which also scales the speed given by motor(Nm) down from the drive $\operatorname{speed}\left(\mathrm{N}_{\mathrm{d}}\right)$. (Figure3)

Simulation consists of variable voltage variable frequency(VVVF) control scheme for induction motor drive. A sinusoidal waveform is compared with triangular carrier waveform to obtain pulses that drive inverter bridge controlling motor input. Modulation index (Ma) controls voltage magnitude and frequency input is given to frequency of sinusoidal signal.

Torque required to drive the vehicle, Td consists of rolling friction, aerodynamic torque and component of weight out of which first two are function of speed. Rolling friction linearly depends on speed whereas aerodynamic torque depends on speed squared. Forces required to overcome by the vehicle are as follows :

Force due to rolling friction:

$\mathrm{Pf}_{\mathrm{r}} \cos (\alpha)$

Aerodynamic drag is calculated as:

$\mathrm{F}_{\mathrm{w}}=0.5 \sigma \mathrm{A}_{\mathrm{f}} \mathrm{C}_{\mathrm{d}} \mathrm{V}^{2}$

Grading resistance:

$\mathrm{F}_{\mathrm{g}}=\mathrm{Mgsin} \alpha$

Where, $\mathrm{Fw}$ is force due to aerodynamic drag in Nm, Af is vehicle frontal area in sq.m., Cd is drag cofficient, $\sigma$ is density of air in $\mathrm{Kg}$ /cubic $\mathrm{m}$., $\mathrm{M}$ is vehicle mass in $\mathrm{Kg}$, $\mathrm{g}$ is acceleration constant, $\alpha$ is angle for uphill slope.

Acceleration resistance is given as

$\mathrm{F}_{\mathrm{a}}=\left(\mathrm{M}+\left(\mathrm{J}_{\mathrm{rot}} / \mathrm{r}_{\mathrm{dyn}}{ }^{2}\right)\right) \mathrm{dV} / \mathrm{dt}$

Where $\mathrm{Fa}$ is acceleration force, $\mathrm{M}$ is mass in $\mathrm{Kg}$, $\mathrm{J}_{\text {rot }}$ is inertia of rotational componants in $\mathrm{Kg}$ *cubic $\mathrm{mtr}$ And $\mathrm{r}_{\mathrm{dyn}}$ is dynamic resistance of the tyre.

Total driving resistance is given as

$\mathrm{F}_{\text {resistance }}=\mathrm{F}_{\mathrm{r}}+\mathrm{F}_{\mathrm{w}}+\mathrm{F}_{\mathrm{g}}+\mathrm{F}_{\mathrm{a}}$

Where $\mathrm{Fr}$ is force due to rolling resistance, $\mathrm{Fw}$ is force due to dynamic resistance, Fg is grading resistance and $\mathrm{Fa}$ is force required for acceleration.

\section{Methodology}

Gear is such designed that it gives high torque (twice of required) during first gear with the help of relay and selector switch in constant torque region of motor. Its ratio becomes 1:1 during second gear.

As rotor speeds required are different for two gears to obtain same $\mathrm{kmph}$, frequency and modulating index values need to be reduced during transition from first gear to second.

Modulation index is gradually increased as frequency is increased which in turn operates motor in constant torque region. Modulation index is saturated at 0.95 to keep voltage from going above rated value thus making motor to operate in field weakening region. [2]

Hence the dynamic equation of the vehicle in motion can be given as $\mathrm{Fa}=\mathrm{Fg}-(\mathrm{Fr}+\mathrm{Fw}+\mathrm{Fg})$

Where Fg is force generated by the engine 
Model Specifications Motor Specifications

\begin{tabular}{|l|l|}
\hline \multicolumn{1}{|c|}{ Type } & Squirrel cage Induction motor \\
\hline Rating & 2 pole, $400 \mathrm{VAC}, 50 \mathrm{~Hz}, 37 \mathrm{~kW}$ \\
\hline Mechanical & $\mathrm{J}=0.37 \mathrm{Kg} \cdot \mathrm{m}^{\wedge}(2), \mathrm{B}=0.02791$ N.m.s. \\
\hline
\end{tabular}

Table 1(a): Motor Specifications

Vehicle parameters

\begin{tabular}{|l|l|}
\hline Tyre & $165 / 85 \mathrm{R} 15$ \\
\hline Weight & $900 \mathrm{Kg}$ \\
\hline Tmax & $500 \mathrm{Nm} @ 1500 \mathrm{rpm}$ \\
\hline Pmax & $50 \mathrm{bhp@2500rpm}$ \\
\hline
\end{tabular}

Table 1(b): Vehicle Parameter

Gear (Synchromesh Type)

\begin{tabular}{|l|l|l|}
\hline No. & Speed range & Gear ratio \\
\hline 1 & $0-42$ & $1: 0.38$ \\
\hline 2 & $42-180$ & $1: 1.29$ \\
\hline
\end{tabular}

Table 1(c): Gear Specifications

\section{Simulation Results:}

For R15 tyre, diameter of the wheel is $15 \times 2.56=38.4 \mathrm{~cm}$. Thus $\mathrm{rpm}$ to $\mathrm{kmph}$ conversion is given as $1 \mathrm{rpm}=$ $\left(38.4 \times 3.14 \times 10^{-2}\right) \times \frac{60}{1000} \mathrm{kmph}=0.072 \mathrm{kmph}$ implying, $1 \mathrm{kmph}=1 / 0.072=13.81 \mathrm{rpm}$. Gear 1 is set to operate for speeds from 0-48kmph while ramping up as shown in Figure 3(a). During this period, modulating index, Ma ramps up from 0.5 to 0.86 so that vehicle achieves desired speed by scaling the motor speed down. At Ma=0.86, motor speed is $1460 \times 0.86=1256.6 \mathrm{rpm}$ which corresponds to $96.58 \mathrm{kmph}$ (linear motor speed for R15 size rotor, same as wheel). Hence gear ratio of 0.49 will make vehicle run at $96.58 \times 0.49=48 \mathrm{kmph}$. As gear ratio changes from 1 to 2 at vehicle speed of $48 \mathrm{kmph}$, speed is scaled up to achieve top speed in field weakening region of second gear as explained earlier. Thus at $48 \mathrm{kmph}, \mathrm{Ma}$ is required to be reduced and increased gradually to maintain desired wheel speeds at same motor rpm. Hence there is sudden drop in Ma on inception of gear 2. After reaching a speed of $104 \mathrm{kmph}$ (Motor speed in $\mathrm{kmph}$ ), Ma saturates while frequency is kept on increasing so that motor can operate in field weakening region to achieve its top speed. Point corresponding to $104 \mathrm{kmph}$ has rotor speed $=1440 * 1=1440 \mathrm{rpm}(\mathrm{Ma}=1)$ that will correspond to $2002.4 \mathrm{rpm}$ at wheel (1:1.45 ratio) which leads to linear speed of $2002.4 / 13.81=145 \mathrm{kmph}$ for the vehicle. Thus to operate vehicle in gear 1 till $48 \mathrm{kmph}$ with $\mathrm{Ma}=0.86$ and attain $145 \mathrm{kmph}$ at $\mathrm{Ma}=1$ and later in field weakening, gear ratio for gear no.1 and 2 are selected as 1:0.49 and 1:1.45 respectively with both wheel and rotor diameter for R15. 


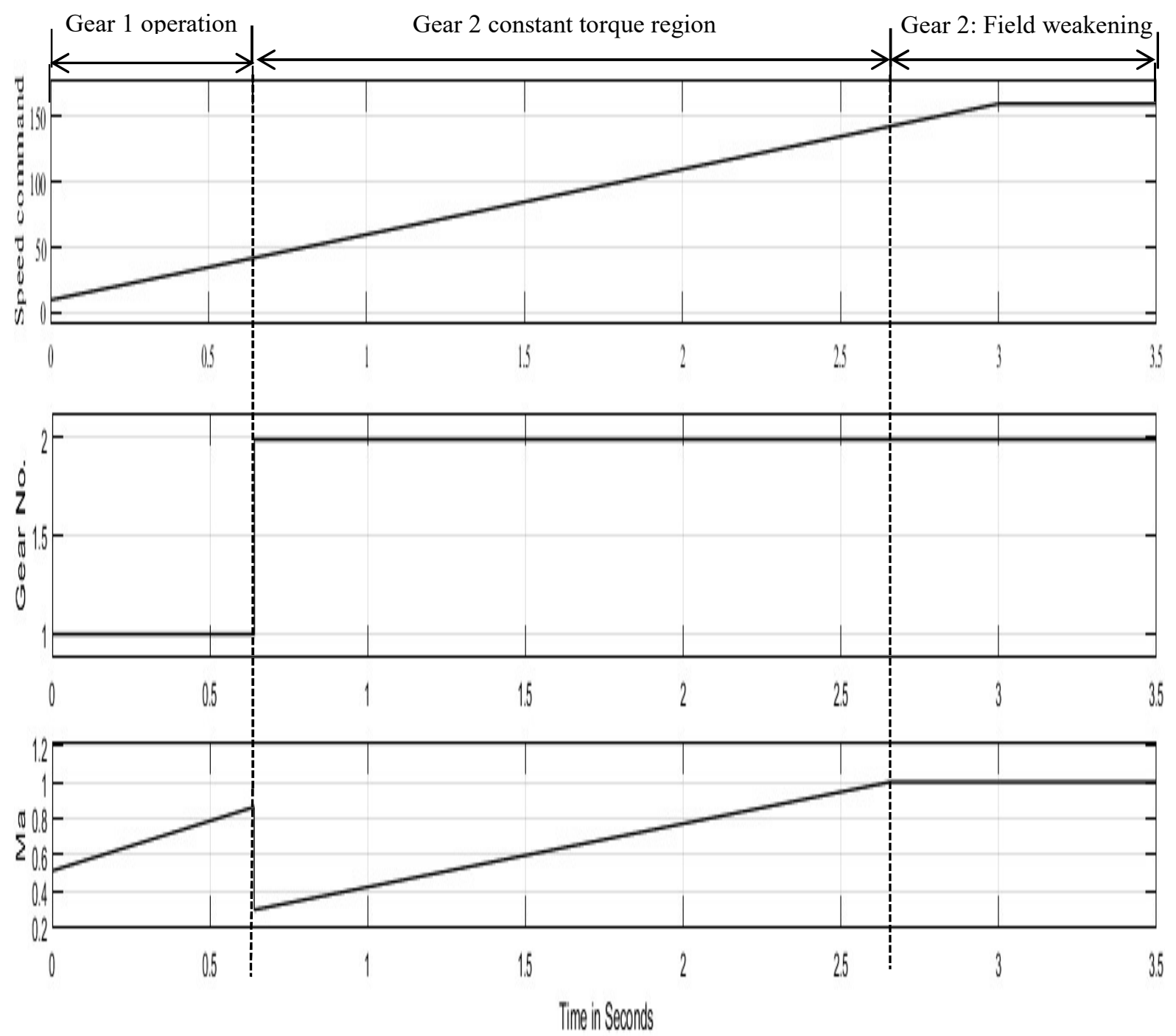

Figure 4 (a): Variation in Ma and Gear no. with respect to Speed Command

As shown in Figure 4 (b), motor torque required to drive the vehicle during first gear is low due to scaling by gear box by the factor of 0.38 . At the end of first gear i.e. at speed close to $42 \mathrm{kmph}$, motor torque is oscillating about $60 \mathrm{Nm}$ which becomes $157.8 \mathrm{Nm}$ at wheel due to gear. This is enough to drive and accelerate the vehicle.

At the end of second gear, motor generates torque of $425 \mathrm{Nm}$ which is marginally below its rated value. The difference between load and electromagnetic torque is lesser than in first gear as the load torque required by the vehicle at maximum speed is $340 \mathrm{Nm}$ thus reducing acceleration of vehicle as it approaches its steady state operating 


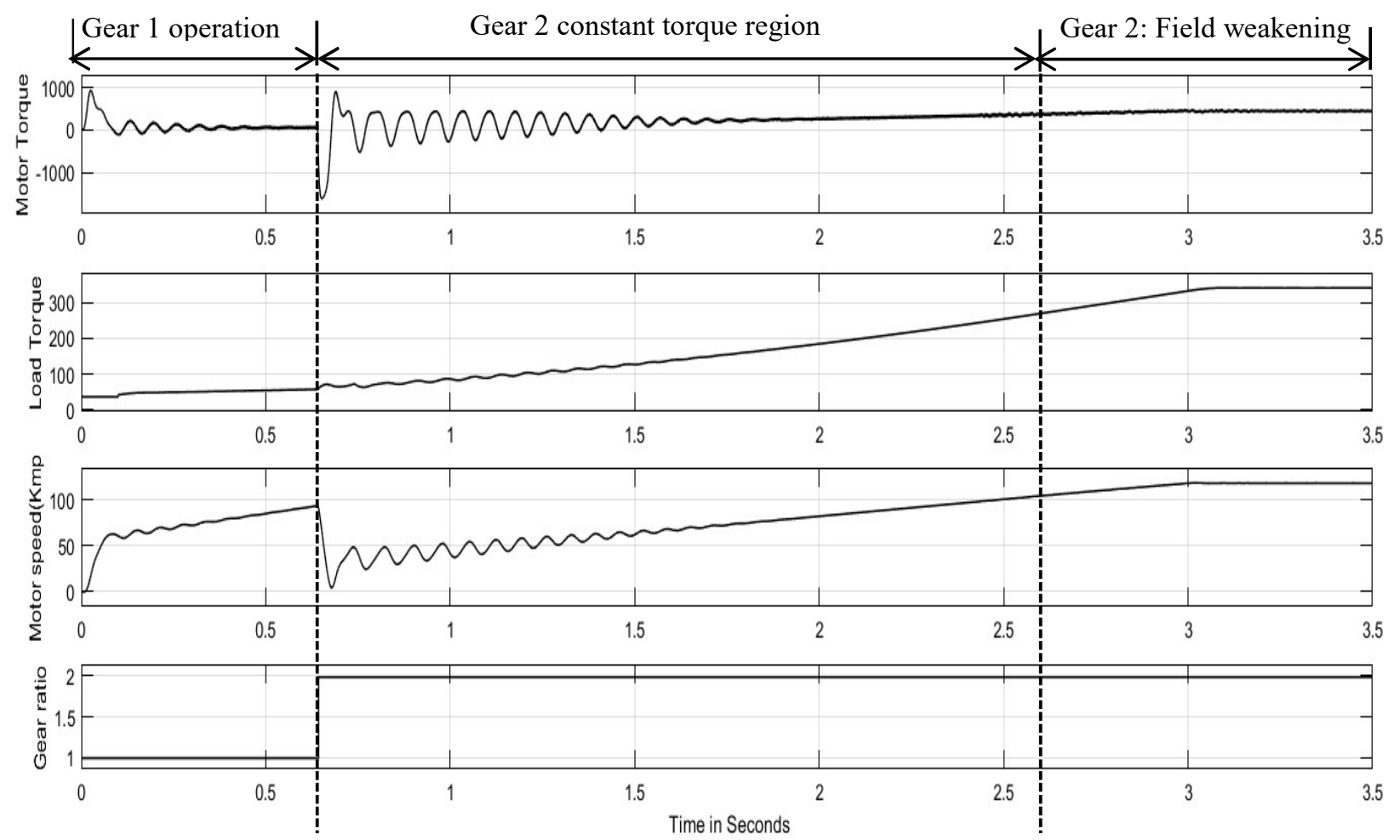

Figure 4 (b): Variation in Motor Torque, Load Torque and Gear no. with respect to Motor Speed

As shown in Figure 4(b), motor torque required to drive the vehicle during first gear is low due to scaling by gear box by the factor of 0.49. At the end of first gear i.e. at vehicle speed $48 \mathrm{kmph}$ (Motor speed $48 / 0.496=104 \mathrm{kmph}$ ), motor torque is oscillating about $60 \mathrm{Nm}$ which becomes $60 / 0.49=122.44 \mathrm{Nm}$ at wheel due to gear. This is enough to drive and accelerate the vehicle.

At the end of second gear, motor generates torque of $425 \mathrm{Nm}$ which is marginally below its rated value. The difference between load and electromagnetic torque is lesser than in first gear as the load torque required by the vehicle at maximum speed is $340 \mathrm{Nm}$ thus reducing acceleration of vehicle as it approaches its steady state operating point.

\section{Conclusion}

Simulation demonstrates Electric vehicle performance showing complete coordination between control, electric power, motor and mechanical components. Effectiveness of gear box in optimizing motor rating is apparent from the results explained. Simulation block can thus suffice load requirement at high speeds as in conventional IC engine driven vehicles and can further be utilized for optimization studies pertaining to various cost, performance, size and energy constrained parameters.

Oscillations in electromagnetic torque of motor causes motor power to oscillate greatly and power is fed back from the motor to the source. Further scope lies in damping the oscillation in electromagnetic torque with power control algorithms. Effect of stiction and accelerating torque required at the start isn't considered in the simulation which will also be required to be taken into the consideration for more practical design for estimation. 


\section{References}

1.Vinten D. Diwakar1, Syrus R. Nedumthaly1, R. Prakash. 2013. Objective Based Modelling and Simulation within a Context of an Electric Vehicle Development Program in EVS27. International Battery, Hybrid and Fuel Cell Electric Vehicle Symposium.

2. Mohammad Bagdadi, Laurent De vroey, Thierry Coosemans, Joeri Van Mierlo. 2013. Electric Vehicle Performance and Consumption Evaluation in EVS27. International Battery, Hybrid and Fuel Cell Electric Vehicle Symposium

3.Anurag M. Lulhe; Tanuja N. Date. 2015. A design and MATLAB simulation used for electric vehicle. International Conference on Control, Instrumentation, Communication and Computational Technologies (ICCICCT) 4. Benjamin Frieske, Matthias Kloetzke, Florian Mauser. 2013. Trends in vehicle concept and key technology development for hybrid and battery electric vehicles. Electric Vehicle Symposium and Exhibition (EVS27)

5.Yu Xiang, Lulu Guo, Bingzhao Gao, Hong Chen. 2013. A study on gear shifting schedule for 2speed electric vehicle using dynamic programming. 25th Chinese Control and Decision Conference (CCDC)

6. Linni Jian, K.T. Chau and J.Z. Jiang. 2008. An integrated magnetic-geared permanent-magnet in-wheel motor drive for electric vehicles. IEEE Vehicle Power and Propulsion Conference.

7.Isabelle Hofman, Peter Sergeant, Alex Van den Bossche. 2013. Drivetrain design for an ultra light electric vehicle with high efficiency. 2013 World Electric Vehicle Symposium and Exhibition (EVS27)

8. P. Spanoudakis, N. C. Tsourveloudis, G. Koumartzakis, A. Krahtoudis, T. Karpouzis, I. Tsinaris. 2014. Evaluation of a 2-speed transmission on electric vehicle's energy consumption. 2014 IEEE International Electric Vehicle Conference (IEVC)

9. C P Prajwal, K Uma Rao, Kishore Ravi Hegde, Shanmukha Nagaraj. 2013. A simple novel algorithm to optimize final gear ratio in electric and hybrid formula racing cars. 2013 International Mutli-Conference on Automation, Computing, Communication, Control and Compressed Sensing (iMac4s)

10. M. T. Peng, S. H. Chien, Y. C. Chung, T. S. Liu, T. J. Flack. 2013. A novel high-torque-density and wide-speedrange hub motor for electric vehicle propulsion. 2013 World Electric Vehicle Symposium and Exhibition (EVS27) 